DOI: http://doi.org/10.21698/simi.2018.ab18

\title{
THE GOLD RECOVERY CLEAN TECHNOLOGY FROM REFRACTORY GOLD ORES USING MICROWAVES' ENERGY
}

\author{
Nicolae Tomus, Marius Zlagnean, Ioana-Carmen Popescu (Hostuc)* \\ National Research and Development Institute for Metals and Radioactive Resources \\ (INCDMRR-ICPMRR), 48 Soseaua de Centura, Magurele, Ilfov County, \\ tomnic90@yahoo.fr, Romania *Corresponding author: janepopescu@gmail.com
}

Keywords: cyanide, gold, microwave, pyrite, "rolling bottle"

\section{Introduction}

Gold recovery from refractory ores has always been a challenge for the scientific community. Low powers' and reagents' consumptions beside the ecological impact's limitation represent the main goals of any highly effective technology. Microwaves' energy is the right answer of those problems.

The present paper aims to present the main research results obtained at the refractory gold-bearing pyrites' microwaving and processing.

The microwaves use's advantages have been pointed out by comparative cyanidation tests carried on microwaved and non-microwaved gold-bearing pyrites samples.

\section{Materials and methods}

INTEC SA in partnership with INCDMRR has accomplished an experimental setup to process the gold bearing pyrite with microwaves in fluidized bed in order to increase the precious metals' extraction efficiency, to decrease reagents' consumption and to save energy.

The experimental setup consists in:

- the microwave generator,

- the waveguide type transmission line,

- the microwave applicator, which is a processing reactor in fluidized bed,

- the fluidizing reagent's supply tank,

- gas-powder separator, which is a cyclone,

- reaction products' neutralizing reactor.

All reagents were analytically grade. Sodium cyanide was used as lixiviation reagent and the lime neutralizing one.

The pyrite was roasted using microwaves at $400^{\circ} \mathrm{C}$ and $700^{\circ} \mathrm{C}$ in order to point out the roasting temperature's effect on gold extraction efficiency and reagents' consumption. The cyanidation was performed using "rolling bottle" method. 


\section{Results and conclusions}

The research results pointed out that when the pyrite was microwaved at $400^{\circ} \mathrm{C}$ there was not any significant decrease in the lime and cyanide consumption in comparison to the non-microwaved ones. When the pyrite has been microwaved at $700^{\circ} \mathrm{C}$ lime's consumption has decreased from $110 \mathrm{~kg} / \mathrm{t}$ to $10 \mathrm{~kg} / \mathrm{t}$, and the cyanide's one from 2.8 $\mathrm{kg} / \mathrm{t}$ to $1.76 \mathrm{~kg} / \mathrm{t}$, respectively.

The gold's lixiviation yields have increased from $50 \%$ in case of non-microwaved pyrite up to $81 \%$ when the pyrite was microwaved at $700^{\circ} \mathrm{C}$.

The sulphur content has decreased from $42.3 \%$ of the non-microwaved pyrite to $25 \%$ in case of pyrite microwaved at $400^{\circ} \mathrm{C}$ and to $15 \%$ for the one at $700^{\circ} \mathrm{C}$.

Sulphur's content diminution to $3 \%$ in order to allow the wet chlorination and to eliminate cyanide's use lixiviation reagent besides the avoidance of slag's production into the resonant cavity should be considered as future research goals. 